\title{
STRUCTURAL AND MAGNETIC PROPERTIES OF FE-OXIDE LAYERS PREPARED BY INKJET PRINTING ON SI-SUBSTRATE
}

\author{
1,2Frantisek ZAZIMAL, ${ }^{3}$ Tomas SVOBODA, ${ }^{3}$ Petr DZIK, ${ }^{1}$ Tomas HOMOLA, ${ }^{2}$ Yvonna JIRASKOVA \\ ${ }^{1}$ Department of Physical Electronics, Faculty of Science, Masaryk University, Brno, Czech Republic, EU, \\ zazimal@ipm.cz \\ 2Institute of Physics of Materials, AS CR, Brno, Czech Republic, EU, jirasko@ipm.cz \\ ${ }^{3}$ Brno University of Technology, Faculty of Chemistry, Brno, Czech Republic, EU
}

https://doi.org/10.37904/nanocon.2020.3682

\begin{abstract}
Magnetic films with two, four, six, and eight layers were prepared using 2D inkjet printing on the $333 \mathrm{~K}$ heated Si-substrates at ambient conditions. The microstructure, phase composition of layers, and magnetic studies were investigated using wide spectrum of experimental methods with the aim to find the optimal conditions for producing magnetic sensors by digital printing technology in the near future. As the magnetic compound, the hematite powder was chosen and its milling with Si-binder dissolved in dowanol using glass balls and vial to prevent contamination was done to prepared suspension appropriate for printing. It is shown that hematite transformed markedly into maghemite, thus the layers consisted of small amount hematite and dominant maghemite phases determining the magnetic properties. From the viewpoint of magnetic behavior, the highest saturation magnetization and the lowest coercivity was obtained at the sample with 8 layers.
\end{abstract}

Keywords: Inkjet printing, hematite, physical properties, testing methods

\section{INTRODUCTION}

The reduction of materials scale leads to profound changes in their inner and surface microstructure and accompanying modification of their physical properties, e.g., electronic, optical, magnetic. In the case of magnetic nanoparticles, the miniaturization often means a deviation from the established laws governing the magnetic phenomena observed in bulk magnetic materials. The current research is oriented to preparation of magnetic nanoparticles using various technological procedures, to their microstructure at the nanometric scale, and to correlations between the microscopic and macroscopic properties. The usual and/or innovative experimental methods allow determination of anomalous or enhanced properties as giant magnetoresistance, coercivity, remanence and magnetocaloric effect enhancements and quantum tunneling of the magnetization, etc. This gives rise to enormous technological usage in, e.g., next generation of very high-density magnetic information storage devices, magnetic sensors, permanent magnets, biocompatible products, etc.

Development of 2D inkjet printing technology enabled to deposit thin layers of materials onto rigid and flexible surfaces. It presently attracts great interest predominantly in the prohexanolduction of low-cost and large-area electronic devices [1]. On the other hand, its usage in the production of magnetic devices is at the very beginning. Among pioneering works, the studies of the magnetic film prepared by a digital printing have to be mentioned. The magnetic film was prepared from the magnetite nanoparticles covered with oleic acid and investigated with the aim to realize magnetic cores for Radio Frequency Identification Resonators [2].

Present work concentrates on the possibility for the production of thin magnetic layer on Si-plate using 2D inkjet printing technology at the temperature slightly above room temperature under ambient atmosphere. The main aim is to produce films of different thickness and to characterize their structure and magnetic properties, 
and to predict the optimal conditions of production in relation to physical properties for future application in magnetic sensors.

\section{EXPERIMENTAL DETAILS}

As an input magnetic material, the commercial hematite nanoparticles of dimension $<50 \mathrm{~nm}$ (Sigma-Aldrich, Steinheim, Germany) was used. The hematite nanoparticles dispersed in dowanol were initially milled with polysiloxane binder dissolved in absolute ethanol [3] using balls in vial; both made of glass to prevent contamination. The aim was to decrease the particle size and to obtain the acceptable suspension. Prior printing on the $333 \mathrm{~K}$ heated Si-substrate at ambient conditions the suspension was in addition dilluted with hexanol. The Si-wafers of different size, corresponding to demands of the subsequently applied experimental methods, were prepared by cutting Si-wafers (100) using spark erosion. The smallest dimension $2.5 \mathrm{~mm} \times 2.5 \mathrm{~mm}$ was used for magnetic measurements, the larger ones, $10 \mathrm{~mm} \times 10 \mathrm{~mm}$, for scanning electron microscopic observations (SEM), X-ray diffraction (XRD), and Mössbauer (MS) measurements.

2D inkjet printing equipment Dimatix Materials Printer DMP-2850 was used for the formation of iron-oxide layers of different thickness; two, four, six, and eight layers $(L)$ were chosen and in conformity with it the samples were denoted $2 \mathrm{~L}, 4 \mathrm{~L}, 6 \mathrm{~L}$, and $8 \mathrm{~L}$. The approximate thickness of layers was determined using profilometer Dektak XT, Bruker.

The morphology of samples was followed by scanning electron microscope MIRA3 (Tescan, Brno) at accelerating voltage of $30 \mathrm{kV}$.

X-ray diffraction patterns were measured at room temperature (RT) using an EMPYREAN diffractometer (Panalytical) with Co Ka radiation $(\lambda=0.17902 \mathrm{~nm})$ in the $2 \theta$ range from $15^{\circ}$ to $130^{\circ}$ in steps of $0.026^{\circ}$ and time per step $\approx 400 \mathrm{~s}$. The evaluation of powder patterns was realized by the Rietveld structure refinement method [4] by semi-automatic mode using the HighScore Plus program and the ICSD database of inorganic and related structures [5]. The phase composition and the lattice parameters were obtained from the pattern analysis.

${ }^{57} \mathrm{Fe}$ Mössbauer spectra at room temperature were taken in the transmission geometry using $\mathrm{y}$-rays and scattering geometry by detecting $7.3 \mathrm{keV}$ conversion electrons (CEMS, [6]) with penetration depth of about $200 \mathrm{~nm}$. Obtained spectra were analyzed using CONFIT program package [7] and calibration of velocity scale was done by a standard thin $\alpha$-iron foil at RT. The transmission geometry was used for measurement of the hematite-suspension soaked in cellulose. Scattering geometry was applied for measurements of the final $2 \mathrm{~L}$ and $8 \mathrm{~L}$ samples.

The magnetic measurements were performed using a Physical Property Measurement System (PPMS) Quantum design, Inc. The hysteresis curves were taken at $300 \mathrm{~K}$ and $2 \mathrm{~K}$ in magnetic field of $\pm 800 \mathrm{kA} / \mathrm{m}$. The zero field-cooled (ZFC) and field-cooled (FC) curves were measured between $2 \mathrm{~K}$ and $300 \mathrm{~K}$ in magnetic field of $8 \mathrm{kA} / \mathrm{m}$.

\section{RESULTS AND DISCUSSION}

\subsection{Sample characterization}

The scanning electron microscope images from all studied samples appear very similarly without any dependence on the layer thickness, as shown in Figure 1 representing the $8 \mathrm{~L}$ (a) and $2 \mathrm{~L}$ (b) samples. The thickness obtained from profilometry scans (not shown here) linearly increased from approximately $2.2 \mu \mathrm{m}$ for the $2 \mathrm{~L}$ sample to $7.5 \mu \mathrm{m}$ for the $8 \mathrm{~L}$ sample. The surfaces of all samples yield small agglomerated nanoparticles of size below $50 \mathrm{~nm}$. The top layers are not fully homogeneous and, in some spots, the pores of dimensions between $50 \mathrm{~nm}$ and $300 \mathrm{~nm}$ can be observed. While in a case of the 8L sample the sub-layers are visible, the similar small pores observed at the $2 \mathrm{~L}$ sample often detect the Si-substrate. 

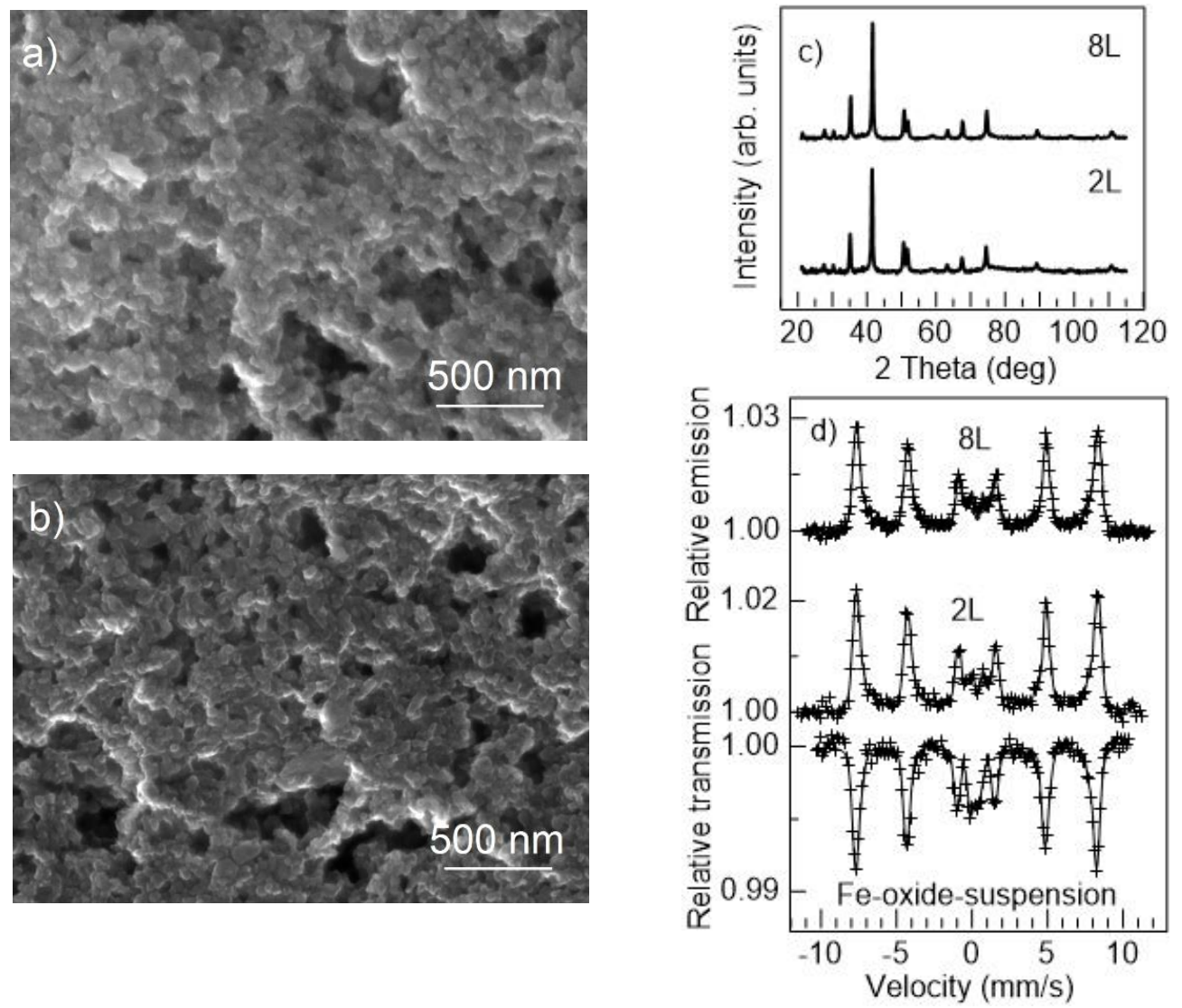

Figure 1 Scanning electron microscope images of the $8 \mathrm{~L}$ (a) and $2 \mathrm{~L}$ (b) samples, powder X-ray diffractograms (c) and Mössbauer spectra (d) of the selected samples

The X-ray diffraction measurements of all samples resulted in very similar patterns and therefore only those for the $2 \mathrm{~L}$ and $8 \mathrm{~L}$ are depicted in Figure 1 (c) as representatives. The diffractograms analysis resulted in a presence of dominant magnetite/maghemite and only minor content of hematite. This stimulated the Mössbauer measurements of the hematite suspension using transmission geometry and of the $2 \mathrm{~L}$ and $8 \mathrm{~L}$ samples using scattering geometry. The spectra are depicted in Figure $\mathbf{1}$ (d) and the results followed from experimental data analysis of both methods are summarized in Tables 1 and 2, respectively.

Table 1 Phase analysis of X-ray diffractograms; $A$ - phase content, $a, b, c$ - lattice parameters

\begin{tabular}{|c|c|c|c|c|}
\hline & \multicolumn{2}{|c|}{ hematite } & \multicolumn{2}{c|}{ maghemite } \\
\hline & $\boldsymbol{A}(\mathbf{w t} \%)$ & $\boldsymbol{a}=\boldsymbol{b}, \boldsymbol{c}(\mathbf{n m})$ & $\boldsymbol{A}(\mathbf{w t} \%)$ & $\boldsymbol{a}(\mathbf{n m})$ \\
\hline 2L & 2.5 & $0.5033(6), 1.3689(20)$ & 97.5 & $0.8346(6)$ \\
\hline 4L & 5.7 & $0.5037(9), 1.3926(38)$ & 94.3 & $0.8336(4)$ \\
\hline 6L & 6.0 & $0.5038(6), 1.3669(22)$ & 94.0 & $0.8336(6)$ \\
\hline 8L & 4.4 & $0.5036(6), 1.3709(23)$ & 95.6 & $0.8350(9)$ \\
\hline
\end{tabular}

Hematite is a common iron oxide with a formula of $\alpha-\mathrm{Fe}_{2} \mathrm{O}_{3}$. It was supposed to be the initial iron-oxide for the present studies; however, the XRD measurements have shown dominant maghemite phase. It is well known that hematite is highly sensitive to various effects; e.g., pressure, external magnetic field, structural defects, impurities, and grain size, influencing its physical properties. For its determination in measured diffractograms the ICSD 15840 sheet with input values of the lattice parameter, $a=b=0.5038 \mathrm{~nm}$ and $c=1.3772 \mathrm{~nm}$, was used. As it follows from Table 1 its content in all samples is low, which reflects its partial transformation into 
dominant magnetite/maghemite phase. It could be very probably caused by induced stresses during milling in a process of the iron-oxide suspension preparation. The magnetite, $\mathrm{Fe}_{3} \mathrm{O}_{4}$, is crystallographically isomorphous with maghemite, $\mathrm{y}-\mathrm{Fe}_{2} \mathrm{O}_{3}$, and both these iron-oxides have cubic structure of similar lattice parameters. Therefore, their determination from diffractogram is not straightforward. For the Rietveld analysis the ICSD data sheets 26410 for magnetite $(a=0.83941 \mathrm{~nm})$ and 172905 for maghemite $(a=0.84058 \mathrm{~nm})$ were used. The resulted values of lattice parameters of both phases did not allow to distinguish between magnetite and maghemite unambiguously. Therefore, the values in Table 1 correspond to weighted mean average.

Table 2 Mössbauer characteristics deduced from the transmission spectrum of the input iron-oxide-suspension and conversion scattering spectra of the $2 \mathrm{~L}$ and $8 \mathrm{~L}$ samples; $A$ - phase content, $B$ - hyperfine induction, $\delta-$ isomer shift, and $\Delta-$ quadrupole shift

\begin{tabular}{|c|c|c|c|c|c|c|c|c|c|c|c|}
\hline \multirow[b]{2}{*}{ Sample } & \multicolumn{4}{|c|}{ hematite } & \multicolumn{4}{|c|}{ maghemite } & \multicolumn{3}{|c|}{ superparamagnetic } \\
\hline & $\begin{array}{c}A \\
(\%)\end{array}$ & $\begin{array}{c}B \\
(T)\end{array}$ & $\begin{array}{c}\delta \\
(\mathrm{mm} / \mathrm{s})\end{array}$ & $\begin{array}{c}\Delta \\
(\mathrm{mm} / \mathrm{s})\end{array}$ & $\begin{array}{c}A \\
(\%)\end{array}$ & $\begin{array}{l}B \\
(T)\end{array}$ & $\begin{array}{c}\delta \\
(\mathrm{mm} / \mathrm{s})\end{array}$ & $\begin{array}{c}\Delta \\
(\mathrm{mm} / \mathrm{s})\end{array}$ & $\begin{array}{c}A \\
(\%)\end{array}$ & $\begin{array}{c}\delta \\
(\mathrm{mm} / \mathrm{s})\end{array}$ & $\begin{array}{c}\Delta \\
(\mathrm{mm} / \mathrm{s})\end{array}$ \\
\hline $\begin{array}{l}\text { Iron-oxide } \\
\text { suspension }\end{array}$ & 10.3 & 50.5 & 0.359 & -0.183 & 75.9 & 49.1 & 0.257 & 0.027 & 13.8 & 0.179 & 0.553 \\
\hline $2 \mathrm{~L}$ & 7.6 & 51.5 & 0.396 & -0.143 & 87.3 & 43.9 & 0.335 & 0.008 & 5.1 & 0.384 & 0.813 \\
\hline $8 \mathrm{~L}$ & 10.1 & 51.3 & 0.412 & -0.164 & 79.8 & 48.1 & 0.331 & 0.011 & 10.1 & 0.372 & 1.162 \\
\hline
\end{tabular}

${ }^{57} \mathrm{Fe}$ Mössbauer spectra recorded at RT were analysed using a conventional least-square refinement method with combination of sextets and doublets of Lorentzian lines. The results shown in Table 2 reflect about $10 \%$ of hematite in the input iron-oxide-suspension represented by sextet of hyperfine parameters, isomer shift and quadrupole splitting, in good agreement with Ref. [9]. The rest is ascribed to magnetically ordered maghemite which documents hematite transformation owing to milling. This confirms the XRD observations and it is supported by Randrianantoandro and co-workers [10] reporting direct phase transformation from hematite to maghemite during high energy ball milling. The doublets in the middle of spectrum can be ascribed to superparamagnetic (SP) portion of iron-oxides in a form of very small nano-grains $(<10 \mathrm{~nm})$. Slightly lower content of this component was detected also in scattering spectra taken from the $2 \mathrm{~L}$ and $8 \mathrm{~L}$ samples in which dominant component was again maghemite. The values of hyperfine induction of hematite correspond to literature but those of maghemite, mainly at the $2 \mathrm{~L}$ sample, are lower. It could be due to slight distortion of crystallographic sites mainly at the particle surfaces and insufficient energy needed for the lattice formation and vacancies reordering. For more detailed analysis, the Mössbauer measurements at low-temperature and, eventually, in an external magnetic field should be helpful.

\subsection{Magnetic results}

The nearly square hysteresis loops of all samples measured at room and low temperatures are shown in Figure 2. The changes of magnetic characteristic, saturation and remnant mass magnetizations $M_{\mathrm{s}}$ and $M_{\mathrm{r}}$ and coercivity $H_{c}$, in dependence on number of layers are presented in Figure 3. The mean values of the coercivity $H_{c}$ and remnant magnetization $M_{r}$ were obtained from the polynomial fitting of hysteresis loops between -60 and $60 \mathrm{kA} / \mathrm{m}$ and $M_{\mathrm{s}}$ was calculated from both branches in saturation (above $\approx 700 \mathrm{kA} / \mathrm{m}$ ). The experimental points were fitted by linear functions (dashed lines) better to see tendency of parameter changes. The dependences (Figure 3) reveal that increasing number of layers (film thickness) leads to an increase of the saturation and remnant magnetizations at both measuring temperatures while the $H_{c}$ embodies an opposite tendency. Such behaviour is not general. For example, in Permalloy film study is the behaviour of magnetic characteristics different bellow and above estimated critical thickness [8]. For the $8 \mathrm{~L}$ sample the saturation mass magnetization is slightly lower compared to values $\left(60-80 \mathrm{Am}^{2} / \mathrm{kg}\right)$ presented for maghemite in literature (e.g. [9]) probably due to influence of the low RT saturation magnetization of weakly ferromagnetic hematite $\left(\approx 0.3 \mathrm{Am}^{2} / \mathrm{kg},[9]\right)$ and reasons mentioned above in discussion of Mössbauer results. 


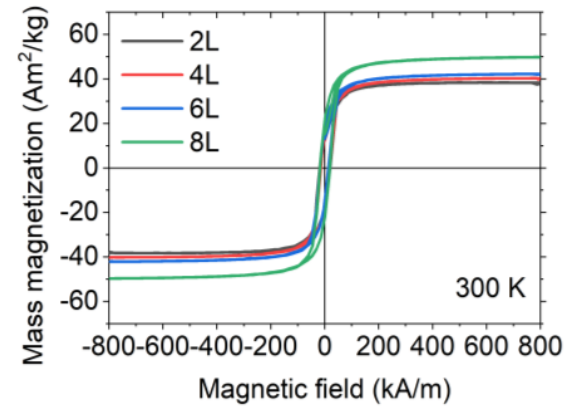

a)

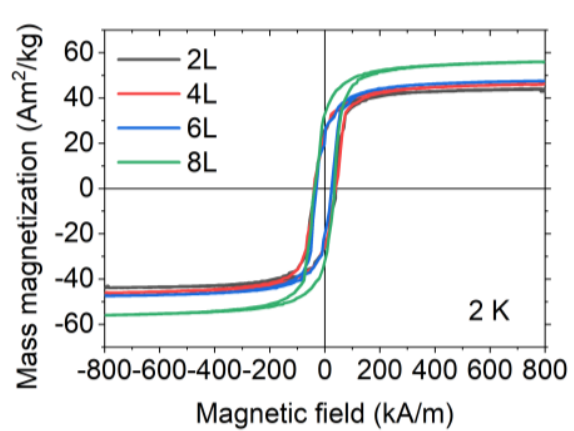

b)

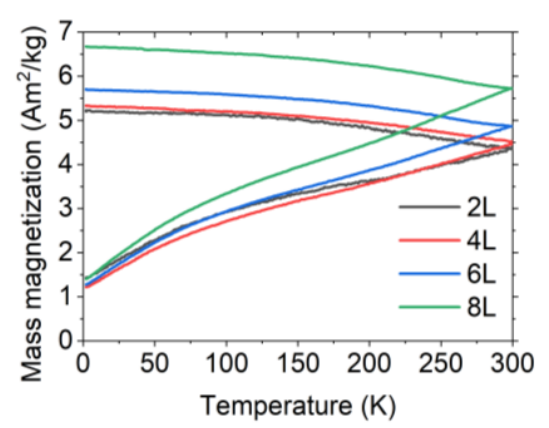

c)

Figure 2 Hysteresis loops of 2L, 4L, 6L and $8 \mathrm{~L}$ samples measured at $300 \mathrm{~K}(\mathrm{a})$ and $2 \mathrm{~K}(\mathrm{~b})$; ZFC-FC curves (c)

The $H_{\mathrm{c}}$ and $M_{\mathrm{r}}$ dependences on number of layers are not so unique compared to $M_{\mathrm{s}}$ due to their high structural sensitivity. The ZFC and FC curves for all samples in Figure $\mathbf{3 c}$ are similar. In agreement with XRD and MS observations they do not provide any sign of Morin temperature being for hematite $260 \mathrm{~K}$ or lower in dependence on particle size.

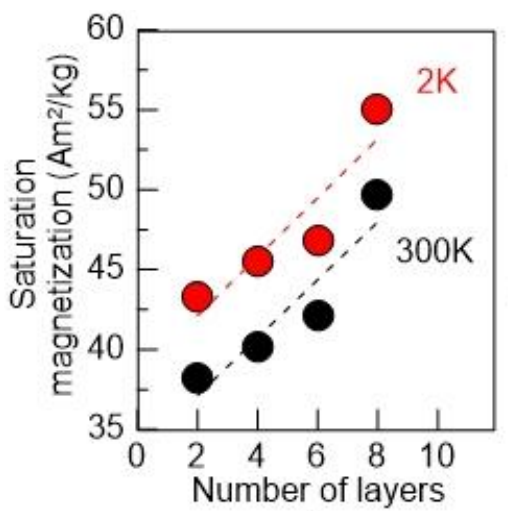

a)

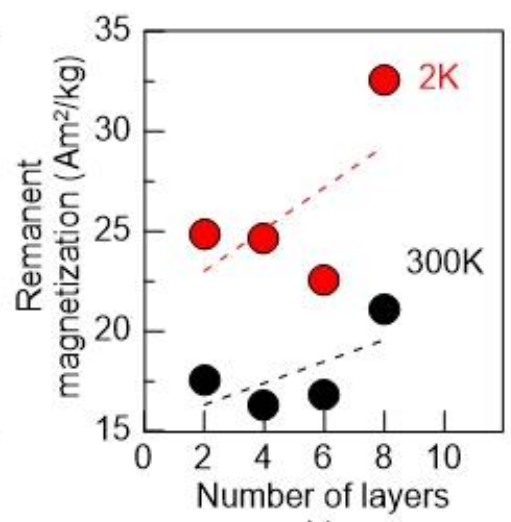

b)

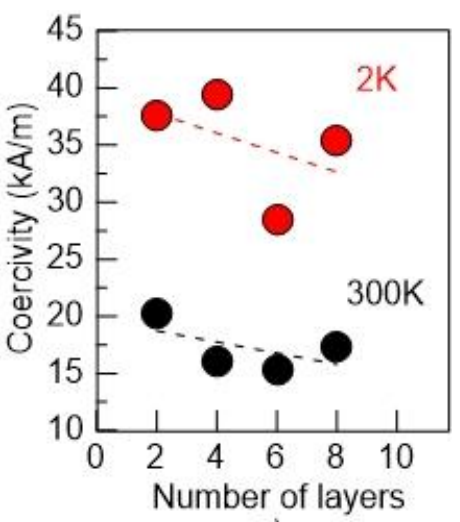

c)

Figure 3 Dependences of saturation magnetization (a), remnant magnetization (b) and coercivity (c) on number of layers taken from hysteresis loops measured at $2 \mathrm{~K}$ and $300 \mathrm{~K}$

\section{CONCLUSION}

The present investigations were devoted to application of the 2D inkjet printing procedure in preparation of magnetic film on the Si-substrate. The hematite powder dispersed in dowanol and mixed with siloxane binder dissolved in absolute ethanol was milled using glass balls and vial with the aim to form suspension applicable for digital printing. The samples with two, four, six, and eight laeyrs of magnetic film were produced and investigated with numerous experimental methods. The scanning electron microscope observations yielded very similar microstructure formed by particles of size below $50 \mathrm{~nm}$ and their agglomerations among them sometimes the pores were visible. These pores detected the Si substrate at the two-layers sample while at the eight-layers sample the bellow laying particles were seen in the pores. It means that cross-sectional homogeneity was not quite satisfactory. The analysis of the X-ray diffraction patterns suppored by Mössbauer phase analysis has found dominant magnetite/maghemite phase and only small amount of the initial hematite in layers of all sample. This transformation of hematite into magnetite/maghemite was found to be initiated during milling in procedure of the suspension preparation. This was subsequently confirmed by high values of saturation magnetization and the measurements of the ZFC-FC curves at which no Morin transition, characteristic for hematite, was observed. From the magnetic viewpoint, the highest saturation magnetization and the lowest coercivity was at the sample with 8 layers. 


\section{ACKNOWLEDGEMENT}

This research has been supported by GACR project 19-14770Y and by CEITEC 2020-National Sustainability Programme II, No. LQ1601. The authors thank M. Hapla from IPM Brno for his help with magnetic measurements and M. Filipska from BUT Brno for the profilometry measurements.

\section{REFERENCES}

[1] ChIOLERIO, A., MACCIONI, G., MARTINO, P., COTTO, M., PANDOLFI, P., RIVOLO, P., FERRERO, S., SCALTRITO, L. Inkjet printing and low power laser annealing of silver nanoparticle traces for the realization of low resistivity lines for flexible electronics. Microelectronic Engineering. 2011, vol. 88, pp.2481-2483.

[2] MARJANOVIĆ, M. N., CHIOLERIO, A., KUS, M., OZEL, F., TILKI, S., IVANOVIĆ, N., RAKOČEVIĆ, Z., ANDRIĆ, V., BARUDŽIJA, T., BAUMANN, R.R. Magnetite nanoparticles: Synthesis, thin film properties and inkjet printing of magnetic cores for inductor applications. Thin Solid Films. 2014, vol. 570, pp. 38-44.

[3] HOMOLA, T., ĎURAŠOVÁ, Z., SHEKARGOFTAR, M., SOUČEK, P., DZIK, P. Optimization of TiO2 Mesoporous Photoanodes Prepared by Inkjet Printing and Low-Temperature Plasma Processing. Plasma Chemistry and Plasma Processing. 2020, vol. 40, pp. 1311-1330.

[4] YOUNG, R. A. (ed.). The Rietveld Method. International Union of Crystallography Oxford University Press Oxford, 1993.

[5] ICSD Database, Version 1.9.4., 2014--1, NIST/FIZ.

[6] GRUVERMANN, I.J. (ed.). Mössbauer effect Methodology. In: SPIJKERMANN, J.J., Conversion Electron Spectroscopy, 1978, Vol. 7, p. 85.

[7] ZAK, T., JIRASKOVA, Y. CONFIT : Mössbauer spectra fitting program. Surface and Interface Analysis. 2006, vol. 38, pp. 710-714.

[8] YOUSSEF, J. B., VUKADINOVIC, N. Thickness-dependent magnetic excitations in Permalloy films with nonuniform magnetization. Physical Review. 2004, vol. B69, no. 17, p. 174402.

[9] CORNELL, R.M., SCHWERTMANN, U. The iron oxides. Weinheim, 1996.

[10] RANDRIANANTOANDRO, N., MERCIER, A.M., HERVEU, M., GRENECHE, J.M. Direct phase transformation from hematite to maghemite during high energy ball milling. Materials Letters. 2001, vol. 47, pp. 150-158. 